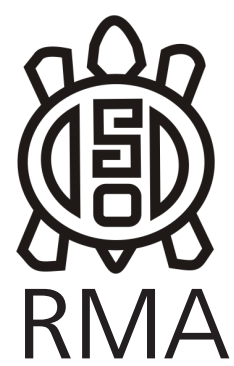

Museología

\title{
Sabios, exploradores y artesanos. Amalgamas del pasado en la Mar del Plata de primera mitad del siglo XX (1924-1954)
}

\author{
Irene Elena Brichetti*
}

*CONICET, Laboratorio de Arqueología Regional Bonaerense, Facultad de Humanidades, Universidad Nacional de Mar del Plata, Argentina. iebrichetti@gmail.com

\begin{abstract}
Resumen
Este artículo analiza la relación entre ciencia, cultura y política, considerando las gestiones realizadas por autoridades políticas del ámbito municipal y la actividad de naturalistas aficionados en Mar del Plata - provincia de Buenos Aires- durante la primera mitad del siglo XX.

El trabajo muestra como una figura preponderante en la escena científica nacional e internacional como la de Florentino Ameghino funcionó a nivel local como modelo moral al cual se le atribuyeron características ejemplares. Dicha imagen se relacionó con la de exploradores autodidactas tales como los integrantes de la familia de Lorenzo Scaglia, quienes se dedicaron a la exploración del pasado natural y humano más lejano de la región. Los aspectos mencionados se pusieron de manifiesto en la prensa gráfica así como en distintos eventos públicos tales como el acto y el desfile inaugural por la instalación de un busto en homenaje a Florentino Ameghino, la exposición en el Salón Witcomb de la Rambla Bristol de los restos fósiles hallados por Lorenzo Scaglia y la formación del primer museo público municipal.
\end{abstract}

Palabras clave: ciencia, estado, modelo moral, sabios, autodidactas

Wise men, explorers and craftsmen. Amalgams of the past in the Mar del Plata of the first half of the $20^{\text {th }}$ century (1924-1954).

\begin{abstract}
This paper Analyzes the relationship between culture, politics and science taking into account the efforts of political authorities and the activities of amateur naturalists in Mar del Plata (General Pueyrredón), during the first half of the 20th century.

This article shows how a great figure in the national as well as international scientific scene such as Florentino Ameghino had function as a model of local morality of exemplary characteristics. The above mentioned image was amalgamated with that of explorers and such self-taught naturalists as the members of the family Scaglia, who dedicated his life to the exploration of the most distant natural and human past of the region. These aspects were revealed in such different public events as the act and inaugural parade by the installation of a bust in honor to $F$. Ameghino, the exhibition in the Lounge Witcomb of the Ravine Bristol of the fossil remains found for Lorenzo Scaglia and the creation of the first municipal museum of the city.
\end{abstract}

Keywords: science, state, moral model, sages, self-tought.

En el transcurso de la última década se han desarrollado investigaciones que ubicaron a los museos como objeto de distintos análisis. Dicho segmento de estudios ha sido abordado desde diversos sectores disciplinares tales como la arqueología, la historia y la antropología. Dentro de ese campo pluridisciplinar, una de las posturas que adquirió mayor relevancia es la que afirma que en Argentina dichas instituciones surgieron como parte de un proyecto político relacionado con la legitimación de los estados nacionales a partir de la constitución de una historia común (Anderson 1993, Podgorny y Politis 19901992, Endere 2008, Endere 2011). Su existencia también se justificaba a partir de la custodia y protección de restos fósiles de megafauna que eran trasladados desde los lugares en que eran hallados hacia núcleos urbanos nacionales o centros científicos europeos donde eran analizados (Endere y Podgorny 1997). Aquellas primeras investigaciones demostraron que para explicar la historia intradisciplinar de las ciencias antropológicas y naturales era necesario conocer los legitimantes ideológicos y los

Recibido 24-04-2012. Recibido con correcciones 04-03-2013. Aceptado 21-02-2014 
elementos relativos al rol del estado pero también, las trayectorias de las principales personalidades de la ciencia, sus prácticas y concepciones dentro de coyunturas políticas y socioculturales variables (Guber et. al 2007, Podgorny 2009).

En ese sentido la relación campo/gabinete, fuertemente establecida en la arqueología y la paleontología hacia fines del siglo XIX, se tornó en un elemento clave para explicar la especialización e institucionalización científica durante todo el siglo XX. La figura del explorador o trabajador de campo que se definía como parte de una amplia red de recolectores y colaboradores apreciados por su conocimiento sobre las áreas de estudio (Pegoraro 2003, Pupio 2011), comenzó a transformarse a medida que ocurría la formalización de saberes y carreras universitarias. El proceso de investigación científico, antes separado entre de campo y de gabinete, pasó progresivamente, a ser de exclusiva responsabilidad de profesionales (Hobsbawm 1996, Ramundo 2008). Es en ese contexto donde emergen diversos reservorios regionales y locales dedicados a la historia natural sobre la base de los hallazgos particulares de aficionados.

Entre ellos se encuentra el primer museo público del partido de General Pueyrredón, cuyos orígenes se sitúan en 1925 con la presentación de un proyecto impulsado por el intendente, Teorodo Bronzini, de crear un Museo de Historia Natural. Paralelamente y bajo el auspicio del mismo sector político, el socialismo, se estaba formulando la discusión para decidir la instauración de un monumento en homenaje al sabio naturalista Florentino Ameghino. Aunque ambas propuestas lograron cristalizarse tardíamente entre 1936 y 1938, en un contexto político y social diferente, aquel fue el antecedente más temprano para la creación de un museo que ya desde entonces contaría con el auspicio del Museo de Ciencias Naturales de Buenos Aires primero y de La Plata después. Aquellas gestiones se hicieron a instancias de un aficionado y coleccionista amateur, Lorenzo Scaglia, quien se dedicaba desde los años veinte a explorar las barrancas costeras en busca de fósiles que extraía, acondicionaba y exponía en su chacra particular. En 1936, como parte del programa de actividades organizado con motivo de la inauguración de un busto a Florentino Ameghino, Lorenzo Scaglia presenta por primera vez su colección en uno de los salones Witcomb de la Rambla Bristol. El evento, que adquiere considerable dimensión, le vale al municipio la posibilidad de contar con una base material para institucionalizar el pasado regional. Sin embargo, para entonces había otros intereses y líneas directrices de orden nacional y provincial, que interaccionan y modifican el proyecto original sucesivamente. De esta forma, el conocimiento acerca de la trayectoria de dicha institución permite abordar la constitución de los campos disciplinares (paleontología y arqueología) desde un lugar poco transitado: el de la actividad de conocimiento práctico realizada por aficionados y denominada como amateurismo. Por otra parte, repara en la formación de un sentido de pertenencia común y en la narrativa de la historia pasada de un municipio y una comunidad política con necesidades institucionales propias de su reciente formación. De ahí que el presente artículo tiene como objetivo general conocer los orígenes del primer museo público municipal y los factores políticos, ideológicos, culturales y científicos implicados en ese proceso.

Los acontecimientos sociales analizados se ubican en el período comprendido entre los años 1924 y 1954, los cuales fueron relevados, de documentos oficiales consistentes en proyectos del Departamento Ejecutivo y discusiones del Concejo Deliberante y; artículos periodísticos tales como editoriales y obituarios aparecidos en diarios locales y de alcance regional' ${ }^{1}$.

\section{Florentino Ameghino y los homenajes a su figura}

"Fue un acto imponente, digno de la vigorosa personalidad del sabio naturalista. Hablaron el doctor Tomás Puig Lómez- cuya conferencia fue leída por Alfredo Torcelli- y el profesor Rodolfo Senet. También se leyó una breve página del doctor Eduardo L. Holmberg y, finalmente pronunció una bella oración José Ingenieros". La cita, que corresponde a Juan Antonio Solari fue publicada en La Prensa en el año 1966 y recuerda el funeral cívico realizado a Florentino Ameghino el 18 de Septiembre de 1911 en el Teatro Argentino de la ciudad de La Plata.

F. Ameghino que había participado en la Revolución de la Unión Cívica de 1890, al igual que Juan B. Justo, se convirtió tras la edición de sus obras por Alfredo J. Torcelli en 1913 y de la publicación de algunos de sus escritos por la Sociedad Luz, en un referente no sólo científico sino también humano ${ }^{2}$. Sin duda, F. Ameghino fue abrazado por el socialismo que reconoció en su trayectoria la de quien sin profesar sus ideas, tenía convicciones éticas, principios científicos y materiales, así como amistades fructíferas con reconocidos socialistas que lo aproximaban a ese campo (Barrancos 1996).

El fervor popular expresado a través de la multiplicidad

\footnotetext{
1 Los diarios y periódicos consultados, conforme a las existencias habidas en la Hemeroteca Pública Municipal del Partido de General Pueyrredón, fueron los siguientes: La Capital (de corte más liberal); El Trabajo (socialista- fundado por Teodoro Bronzini) y El Progreso (tendencia conservadora). También se accedió a La Hora (edición de La Capital) y, en otros reservorios, a Germinal, publicación socialista de la localidad de Tandil, así como a revistas científicas tales como la del Museo de Ciencias Naturales de Mar del Plata y de La Plata.

2 Dora Barrancos explica que si bien Florentino Ameghino no formó parte del socialismo, mantuvo lazos de amistad o de colaboración en diversas instancias con hombres que si lo eran o que tenían una abierta simpatía por las ideas de dicho campo político. Entre los mencionados se encuentran: Rodolfo Senet, Juan B. Ambrosetti, Ángel M. Giménez y Victor Mercante. Con respecto a la edición de sus obras, cabe destacar que Alfredo Torcelli fue secundado por Carlos Ameghino. Lo mencionado en el texto se debió a un encargo realizado por la provincia de Buenos Aires para la edición de la totalidad de sus obras (1913) aunque también se encargaron de otras dos ediciones.
} 
de los homenajes públicos realizados en su memoria, no se agotó en dicho enclave del arco político sino que se extendió a otros sectores tales como el liberalismo, el conservadurismo y, el nacionalismo. La imagen póstuma del sabio proclamada por los sectores socialistas se sostuvo por un lado en una férrea defensa por la educación laica y, por otro, en la popularización del conocimiento. Cabe destacar que lo educativo fue un aspecto muy discutido en todo el arco político de la época, especialmente defendido por el socialismo $y$, rebatido por el conservadurismo -católicos y/o nacionalistas- del período de entreguerras.

Un aspecto sugerente de esas disputas lo conforma el acuerdo en el culto a F. Ameghino y la intención de continuar con una tradición inaugurada con la celebración de personalidades tales como la de Francisco Muñiz y Charles Darwin a quienes tanto Domingo Sarmiento como el mismo Florentino Ameghino habían contribuido a entronizar en la escena pública nacional (Podgorny y Farro 1998). En ese sentido podría decirse que la figura de Ameghino se amalgamó con la de Sarmiento ya que mientras la historiografía liberal lo entronizó en la categoría de "self-made-man" con la cual ambos personajes fueron perpetuados, el socialismo refería con ello al legado propio del socialismo utópico que lo ligaba con Sarmiento, pero también con Esteban Echeverría, Juan Bautista Alberdi, Juan María Gutiérrez, Manuel Quiroga Rosas entre otros, a los cuales José Ingenieros denominó como los "saintsimonianos argentinos" (García Costa 1997). Podría decirse que mientras para los socialistas la imagen de F. Ameghino se traducía en promesa para el acceso popular al conocimiento, para los liberales y aún para los conservadores, era una coyuntura favorable para promover ideales como la austeridad y el altruismo atribuido a los próceres nacionales a través de la historia escolar y el normalismo. La intención de transformar a F. Ameghino en un modelo de virtud moral (Podgorny 1997) también implicó una síntesis de su figura que lo despojó de aquello que podría generar algún atisbo de conflicto entre lo que los diversos sectores políticos buscaban resaltar. De ahí que analizar el inicio del culto público al sabio se escinde de su biografía y de las comparaciones entre su vida y la constitución póstuma de su imagen, que fue variando según las constelaciones político-sociales circundantes. Es en ese sentido que podría decirse que en su figura se fusionó la del estado a través de la pompa oficial por un lado, y de la multiplicación de reconocimientos en distintos ámbitos culturales y científicos, por otro.

En el plano científico estuvo particularmente implicada la situación disciplinar de la arqueología y la paleontología entre fines del siglo XIX e inicios del XX, cuando tomaron un rol preponderante en la conformación de una ciencia de carácter nacional (Endere 2008). La importancia otorgada a los estudios sobre las evidencias fósiles no sólo no se mantuvo ajena al propósito de proyección de la gloria atribuida a la nación argentina, sino que se consagró como uno de los elementos constitutivos de la nacionalidad (Endere y Podgorny 1997, Podgorny 2000). De esta forma, las instituciones escolares mediatizaron la articulación entre saber y poder que condujo a la legitimación de un nuevo orden social fundado en el fortalecimiento de la profundidad histórica de la nación así como en el ejemplo de sus grandes hombres (Carretero 2007, Romero 2004, Bertoni 2001). La presentación de la imagen de F. Ameghino como arquetipo moral no se agotó en los aspectos relativos al ideal cívico/nacional que se buscó instalar, también se sumó a la adopción de un modelo pedagógico que condensó pautas de conducta y formas de disciplinamiento social.

Asimismo, el culto al sabio tampoco se limitó a la representación de ideales cívicos e incluso morales ya que la influencia de la obra ameghiniana sostuvo el establecimiento de formas de hacer aceptadas en el ámbito científico. Tanto Carlos como Florentino Ameghino lograron al mismo tiempo distinguir y conjugar exitosamente la labor de campo y la del gabinete en tiempos en los cuales las prácticas de los exploradores, viajeros y naturalistas eran aún muy heterogéneas y difusas.

De esa forma, la muerte de Ameghino implicó el recrudecimiento de viejas discusiones que, aunque superadas en los ámbitos especializados, continuaron circulando en otros contextos. A inicios del siglo XX, ya convencidos sobre la convivencia de los primeros grupos de cazadores-recolectores con la megafauna extinta, la incertidumbre en los debates cognitivos giraba en torno a la antigüedad de los primeros habitantes del sur americano. F. Ameghino había contribuido en el análisis de sendos problemas mediante su participación continua y conspicua en los círculos científicos internacionales (Podgorny 1997, Daino 1979, Bonomo 2002).

Así, la imagen de F. Ameghino se fue imbricando tanto en los espacios vinculados a la ciencia como también con la estructura educativa del normalismo, transformándose así en parte del soporte legitimante del estado hacia iniciativas de carácter científico y cultural.

\section{El sabio en escena local}

El 15 de junio del año 1925 la Municipalidad del Partido de General Pueyrredón, por intermedio del Concejo Deliberante, sancionó mediante ordenanza el proyecto para el esculpido de una escultura en homenaje al "sabio naturalista Don Florentino Ameghino"3. La iniciativa databa de un año atrás cuando, en ocasión

\footnotetext{
3 Boletín Municipal [en adelante BM], "Ordenanzas SancionadasEstatua a Florentino Ameghino", Mayo y Junio de 1925: 17 / Diario La Capital, La Sesión del Cuerpo Deliberativo Municipal tuvo ayer un final inesperado. La contribución municipal para la erección de una estatua al naturalista argentino, 23/05/1925, MDP.
} 
del cincuentenario de la fundación del pueblo de Mar del Plata, se había colocado durante acto público la piedra fundamental sobre la cual se esculpiría el rostro del mencionado naturalista 4 . La propuesta había sido presentada por el entonces presidente del Concejo Deliberante, el concejal socialista Gaudenzio Orazi, quien más tarde se convertiría en uno de los principales promotores del homenaje local a F. Ameghino ${ }^{5}$. La prensa gráfica consideraba la idea como "un motivo de estímulo para la difusión de conocimientos científicos de saludable y alto valor moral"6.

Al mismo tiempo, calificaba dicha oportunidad propicia para desalentar a quienes consideraban a Mar del Plata como "una ciudad de un espíritu mercantilista acentuado, despreocupada, agena [sic.] a las altas especulaciones de la cultura y la ciencia ${ }^{7 "}$. En efecto, hacia 1920 se inicia un notable proceso de pujanza económica política y social basado en la industria y el comercio pero también en el turismo. Dicho desarrollo convierte a la villa balnearia de las clases altas de inicios del siglo en una ciudad de mayor accesibilidad por efecto de la inmigración y de las políticas de planificación económica y social -que se inician con la política de sustitución de importaciones de la década del treinta y que se acentúa en las posteriores. El pueblo que diera origen a la villa balnearia de las elites porteñas de inicios de siglo, había sido creado en 1874 y declarado como ciudad en 1906; pasarían más de cuatro décadas hasta que Mar del Plata se constituyera en el núcleo urbano popularmente conocido durante los años cincuenta (Da Orden y Pastoriza 1991, Bartolucci 2002, Pastoriza 2008).

Los festejos populares eran habituales en la escena pública municipal y se entremezclaban con las conmemoraciones propias del calendario nacional. La comuna se esforzaba por incentivar los ámbitos de sociabilidad públicos en cada ocasión que consideraban benévola para contribuir a forjar un sentido de pertenencia común que distinguiera a la comunidad local en el contexto bonaerense y nacional más allá de su condición turística y balnearia.

El proyecto, pensado por el socialismo entre 1924 y 1925, se concretó en 1936, en un escenario político dominado por el conservadurismo. El programa oficial fue anunciado los días previos a través de la prensa gráfica local donde se invitaba al público en general a

\footnotetext{
${ }^{4}$ BM, Festejos del Cincuentenario de Mar del Plata- Monumento a Florentino Ameghino-Acta de la colocación de la Piedra Fundamental. Enero y Febrero de 1924: 10-11, MDP.

${ }^{5}$ Diario La Capital, Mar del Plata debe perpetuar en el bronce la obra del sabio F. Ameghino, 21/06/1925, MDP.

${ }^{6}$ La Capital, La contribución municipal para la erección de una estatua al naturalista argentino, 23/05/1925, MDP.

${ }^{7}$ La Capital, La contribución municipal para la erección de una estatua al naturalista argentino. 23/05/1925, MDP. Para conocer el proceso histórico de Mar del Plata durante la primera mitad el siglo XX ver: Pastoriza 2008, Pastoriza y Torre 1999. Desde una perspectiva más general ver AAVV, 1991, Mar del Plata. Una Historia urbana. Fundación del Banco de Boston.
}

los eventos inaugurales. El intendente municipal, José Camusso, llamaba a la población a: "asociarse a todos los actos de significación popular que se tributen a la memoria del esclarecido sabio" al tiempo que contribuir para que el homenaje "adquiera contornos de excepcional lucimiento". Además, se cursaron invitaciones particulares a las principales personalidades de la cultura, la política y la ciencia de la provincia.

El día 30 de noviembre de 1936 las actividades oficiales comenzaron temprano en la mañana cuando las autoridades locales, junto a representantes de la Asociación de Maestros, recibieron al gobernador de la provincia, Manuel Fresco, y, a la comitiva oficial en la Estación Norte del Ferrocarril. Entre las autoridades y personalidades que viajaron especialmente al evento se encontraba el gobernador de la provincia y dos de sus ministros, el director del Instituto del Museo de Ciencias Naturales de La Plata y familiares de Ameghino. También asistieron las autoridades del municipio colindante de Miramar. El acto inaugural se efectuó en la zona conocida como Punta Iglesia, sobre la costa, sitio de emplazamiento final de la efigie, tras diversas discusiones. A su turno, el intendente municipal, J. Camusso, el ministro del Interior, R. Noble y el entonces director del Museo de La Plata, J. Frengüelli, tomaron la palabra. Los discursos de los mencionados pusieron de manifiesto aspectos concernientes a la caracterización póstuma de la figura del sabio tales como la moral del trabajo, la autodidaxia, la austeridad y el desinterés del estado hacia una labor naturalizada como desinteresada y altruista. Los funcionarios que recordaron a F. Ameghino priorizaron su doble actividad como comerciante en el negocio familiar y educador, a través de su puesto de preceptor, resaltando siempre su cariz modesto y austero como cualidad ejemplar. Por ejemplo, el discurso del ministro de gobierno, R. Noble, se caracterizó por la mención de la labor comercial y del oficio de librero que se vinculaba con la exitosa conjunción que entre ciencia y otras actividades realizaban los naturalistas entre fines del XIX e inicios del siglo $X X^{8}$. De hecho, las décadas comprendidas entre 1910 y 1940 fueron testigos del surgimiento de una generación de coleccionistas de fósiles y antigüedades relacionada con el comercio, los almacenes, el mundo del trabajo y la política (Barrancos 1996, Podgorny 2004). El complejo sistema de redes interpersonales así como los itinerarios de los comerciantes viajeros también favorecieron las conexiones locales con puntos geográficos equidistantes ya que acercaron las áreas de campo a los gabinetes de investigación (Farro 2008).

Otro elemento que se desprende del discurso de R. Noble corresponde a las situaciones de marginación y pobreza que F. Ameghino habría vivido en función de una tardía comprensión por parte del estado hacia el valor de la ciencia nacional (Podgorny 1997). La difusión de lo

${ }^{8}$ BM, Homenaje a Florentino Ameghino. Cuarto Trimestre, 1936: 208218. 
a

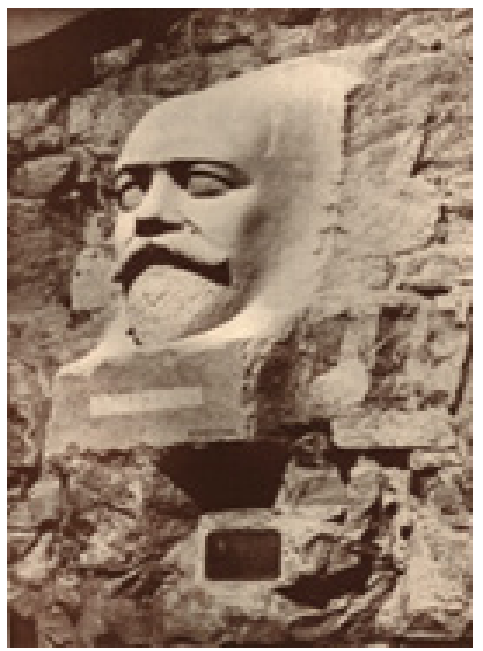

b

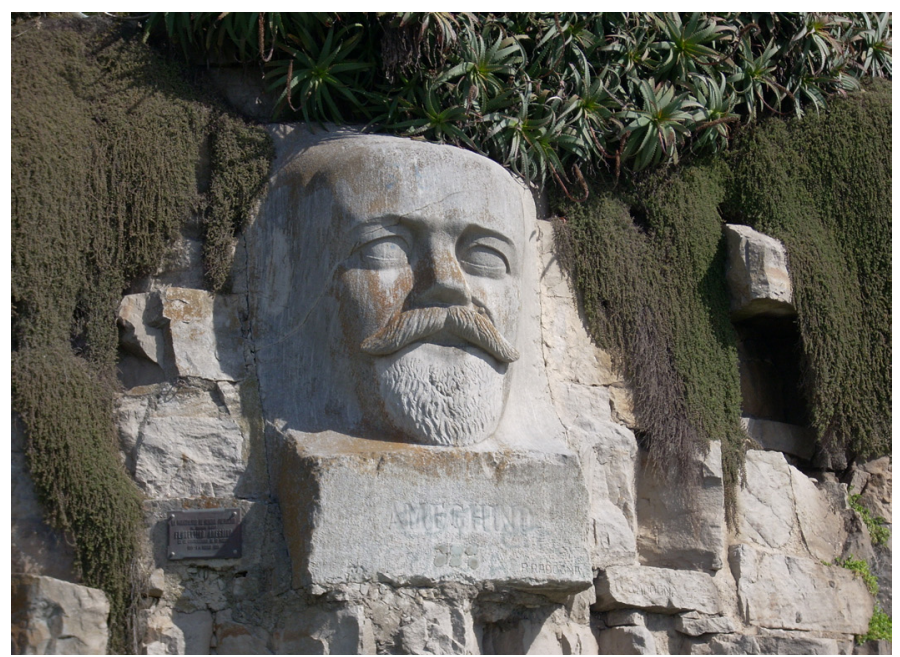

Figura 1.a. Fotografía de la efigie de Florentino Ameghino, realizada por Radogna y publicada en la portada del Boletín Municipal No 82 del año 1936. b. Estado actual de la misma efigie.

Figure 1.a Photograph of Florentino Ameghino's bust, taken by Radogna and published on the cover of the Municipal journal $\mathrm{N}^{\circ} 82$ in 1936. Current status of the effigy.

anterior ayudó a instalar una imagen no sólo altruista sino austera que el ministro de gobierno administra al referir que F. Ameghino debió "ganar el pan de cada día con el sudor de su frente. Ejemplares insustituibles de su colección fueron a parar a los museos extranjeros, que hoy los ostentan con orgullo, decorando sus vitrinas en nombre de Ameghino". La omisión del estado se traduce aquí en las palabras de los distintos funcionarios, los cuáles fluctuaban entre la admiración hacia la obra de F. Ameghino y el intento por subsanar el olvido del estado hacia la ciencia mediante el reconocimiento hacia la figura cívica ejemplar. En el sentimiento de arrepentimiento encarnado en la palabra de sus administradores subyace la pérdida de lo que podría considerarse el patrimonio público nacional en museos extranjeros (Endere y Podgorny 1997).

Un cuarto aspecto que aparece retratado tanto en la prensa gráfica como en los discursos lo conforma la intención de equiparar la figura del sabio y la de Sarmiento a partir de la reedición de aspectos compartidos tales como el carácter autodidacta de ambos. El hecho que F. Ameghino fuera descendiente de italianos nacido en el país, su educación el resultado del pasaje por las instituciones escolares argentinas, y, su obra de importancia internacional, son aspectos que lo categorizan como prócer nacional, científico popular y educador de las multitudes. Como personalidad pionera de la ciencia, su existencia confirma para vastos sectores la excelencia del modelo educacional y su función productora del ideal cívico nacional. Además, siendo F. Ameghino egresado de la escuela normal y D. Sarmiento su creador, la ciencia en vías de formación no sería sino hija de aquel primer educador y por ende, del proyecto fundacional de la nación ${ }^{9}$.

\footnotetext{
${ }^{9}$ La Capital, Mar del Plata inmortaliza en la piedra la figura prócer del
}

El acto inaugural, amenizado a partir de las intervenciones verbales de los distintos funcionarios, se nutrió de la biografía de Ameghino para apelar a la nacionalidad y descansar finalmente en el sentido común de pertenencia local. Así, Joaquín Frengüelli rescató del olvido las discusiones ya superadas acerca de los hallazgos obtenidos en Punta Hermengo y Chapadmalal quizás como recurso retórico para resaltar la profundidad temporal de la nacionalidad ${ }^{10}$. La figura del sabio, sus descubrimientos y el territorio argentino confluyeron en la pretensión de un sentimiento nacional asociado a la idea de un pasado remoto y a la proyección política e ideológica de la nación (Podgorny y Politis 1990-1992, Masotta 2007) reproducida a través de las instituciones de educación formal y no formal (Conforti 2010).

Esa construcción ficticia que denominamos nacionalidad confluye a través de la imagen del científico popular y del educador nacional en diversidad de sentidos posibles e impensados. Detrás de lo identitario se encuentra el interés que el intendente J. Camusso observó en la posibilidad de impulsar el aprovechamiento de la llamada piedra Mar del Plata, especial por su riqueza calcárea y posibilidades de aleación y absorción para la pavimentación de caminos. En ese sentido, la entronización de la figura del sabio se apreciaba también como una oportunidad para estimular la explotación de las canteras zonales ${ }^{11}$. En su intervención el intendente señaló la prodigalidad de la naturaleza ambiente que había posibilitado la materialización

\footnotetext{
sabio Florentino Ameghino, 29/11/1936.

10 Revista del Museo de La Plata, Nueva Serie. Sección Oficial, Inauguración del Monumento a Florentino Ameghino, 1937: 114-117. 11 Diario El Progreso, La Piedra de las canteras de Mar del Plata se presta perfectamente para el difícil trabajo de su manipuleo artístico, 5/03/1936, MDP.
} 
artística del recuerdo de F. Ameghino ${ }^{12}$.

Además de los discursos se emplearon otros dispositivos orientados hacia la recreación en el plano local de la gloria nacional atribuida a la ciencia y desarrollada por las entidades educativas. Como parte del programa de actividades anunciado previamente, se efectuó un desfile público escolar protagonizado por alumnos de la Escuela Normal Municipal y por la Escuela Municipal de Artes y Oficios.

Luego de la mención de los atributos morales del sabio así como de su contribución a la formación del ideal cívico nacional, llegó el espacio para la presentación de la exhibición de fósiles de Lorenzo Scaglia en uno de los salones Witcomb de la Rambla Bristol. Así se refería la prensa local a la misma: "se realizará una interesante exposición de fósiles encontrados en esta región por el vecino Sr. Scaglia, quien desde hace años viene trabajando en la formación de un valioso museo de Historia Natural". La exhibición referida fue la última actividad oficial con presencia pública realizada con motivo de la inauguración. Por la tarde, hubo una recepción en el Club Náutico de la ciudad y un Banquete en honor al gobernador en el Hotel Royal donde tomó la palabra el concejal Agustín Rodríguez quien aludió nuevamente a la modestia y al trabajo desinteresado del sabio como aporte a la gloria nacional. Por su parte, el gobernador Manuel Fresco retomó las palabras invitó a reflexionar conjuntamente en la acción moral, la educación y los símbolos patrios, entrelazando de esa manera, la educación formal con los sentimientos nacionalistas. Las palabras de M. Fresco cobran mayor sentido si consideramos que se trata de una época marcada por un conservadurismo vinculado con el nacionalismo, la política dirigida y el fomento a la obra pública. El fresquismo aunque difería del socialismo ampliamente, también presentaba un marcado interés por los sectores populares. Esa coincidencia coyuntural se veía, no obstante, tensionada por la disputa acerca de la enseñanza religiosa y el laicismo en las escuelas públicas (Jofre et. al 1991):

"Nos hemos preocupado intensamente del niño: de su educación nacionalista de despertar en él el amor (...) donde ha nacido, el respeto a los símbolos, el cariño a la tierra, el culto a la bandera (...) Condición espiritual alcanzada para el bien de esta provincia, comprendida con amplia generosidad por los maestros de Buenos Aires y muy especialmente los maestros de Mar del Plata, centro social acechado permanentemente por el desquicio y el desorden promovido por las izquierdas que nada tienen que perder".

Finalmente habló el historiador y ex-intendente Julio C. Gascón que enfatizó en el progreso edilicio de Mar del Plata y en la importancia dada al fomento de la cultura

\footnotetext{
${ }_{12}$ BM, Homenaje a Florentino Ameghino. Discurso del Intendente Municipal. Cuarto trimestre, 1936: 210.
}

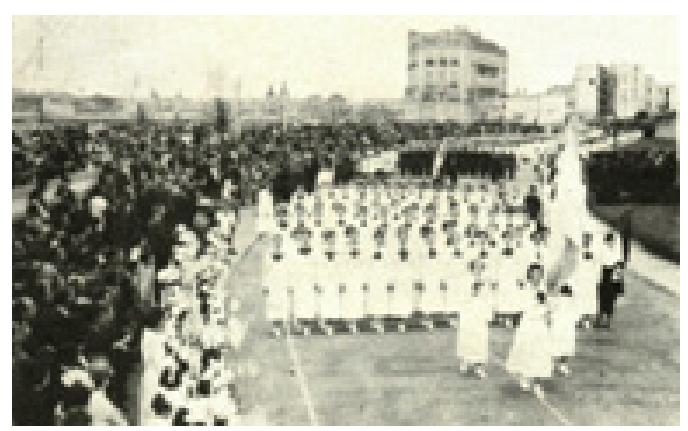

Figura 2. Imagen del Desfile Escolar tomada en ocasión de la inauguración del Monumento a Florentino Ameghino, publicada en el Boletín Municipal Nº 82, con fecha 30 de Noviembre de 1936.

Figure 2: Picture of the School March taken during Florentino Ameghino's museam inauguration, published on the Municipal journal on November 30th in 1936.

popular. Las actividades de cierre estuvieron dadas por un acto de carácter artístico/cultural convocado y realizado por miembros de la Corporación Nacionalista de Maestros en el Teatro Colón de la ciudad y; como último acto de la jornada, se realizó un baile popular.

Durante los actos en homenaje confluyeron elementos y posicionamientos políticos divergentes, producto de las distintas jerarquías de la administración municipal y provincial que, sin embargo, armonizaron por su interés común en la celebración de la nacionalidad y de un sentimiento compartido de ciudadanía local.

\section{El primer Museo Público y Regional}

El proyecto de esculpir sobre la piedra fundamental de Mar del Plata un busto a F. Ameghino se complementaba con la idea de crear un Museo de Historia Natural:

"Sería, a nuestro juicio, poco honroso para el vecindario y para la municipalidad de Mar del Plata, dejar trunco tan bello propósito restando de tal suerte a la ciudad de una obra de ornato que, aparte de su valor artístico, significa perpetuar la memoria del sabio esclarecido, cuya ciencia y contracción ejemplar abrirá un nuevo y vasto horizonte al museo de historia natural"13.

El Museo de Historia Natural cuya creación se dispuso por decreto el intendente electo Teodoro Bronzini nacía al amparo del modelo de civilidad ejemplar del sabio ${ }^{14}$. El proyecto ${ }^{15}$ correspondía al primer Museo Municipal

\footnotetext{
${ }^{13}$ La Capital, La Sesión del Cuerpo Deliberativo Municipal tuvo ayer un final inesperado. La contribución municipal para la erección de una estatua al naturalista Ameghino, 23/05/1925, MDP.

${ }^{14}$ La Capital, Sesión de ayer del Concejo Deliberante. Mensaje y Proyecto del D.E. creando un Museo de Historia Natural, 30/05/1925, MDP.

15 BM, Creación de un Museo de Historia Natural. Proyecto del Departamento Ejecutivo elevado al Honorable Concejo Deliberante, Mayo y Junio de 1925: 7-8.
} 
que, con fines de cultura popular, estaría destinado a la reserva de materiales de historia natural, arqueología de la región y de las aplicaciones modernas del trabajo humano, las industrias agropecuarias y la pesquera. La institución contaría con una comisión honoraria de cinco miembros -uno en representación de la Municipalidad y el resto vecinos de la localidad- y el patrocinio del Museo Nacional de Historia Natural de Buenos Aires que se había comprometido a "hacer entrega, una vez hechas las instalaciones del museo municipal, de algunas colecciones que aquel museo tiene por duplicado ${ }^{16 "}$. También contaría con un encargado-preparador que sería el responsable de custodiar y mantener las condiciones del material en reserva.

La iniciativa se gestaba a la par del surgimiento de diversas sociedades tales como el primer Ateneo de Mar del Plata denominado Ciencia, Arte y Trabajo o la Asociación de Maestros, todas ellas impulsadas por el socialismo que dominó la escena pública local durante la década de 19209. Aunque aquel museo no prosperó, sentó las bases de la institución municipal que se crearía a instancias de un aficionado, Lorenzo Scaglia, que por esos mismos años iniciaba tareas de recolección en las barrancas costeras en busca de fósiles. En 1930, el entonces director del Museo de Ciencias Naturales de La Plata, Luis María Torres, le encomendó la excavación y extracción de restos fósiles en las costas de Mar del Plata, para lo cual le ofreció la colaboración de dicha institución ${ }^{17}$. Pero el mayor premio a su labor se dio cuando presentó su colección en 1936 frente a autoridades y público en general en uno de los salones de la Rambla Bristol durante el ya mencionado homenaje.

Aquella Primera Exposición Paleontológica organizada por L. Scaglia fue de las que revistió mayor relevancia tanto por la atención que la prensa local y nacional le otorgó, como por los elogios que cosechó por parte de las autoridades que asistieron a los actos. Aún muchos años después, la exhibición era recordada como un "generoso y patriótico esfuerzo por dotar a Mar del Plata y al país en general de un acervo científico de importancia en el campo de las ciencias naturales ${ }^{18^{\prime \prime}}$. La repercusión de dicha exhibición significó la concreción del Museo Regional, Histórico y Tradicional de Mar del Plata. Aquel primer museo se inauguró el 22 de noviembre de 1938 y funcionó en un local acondicionado a tal fin dentro del mismo Palacio Municipal ${ }^{19}$.

Dicha institución respondía a un anhelo postergado por años principalmente por L. Scaglia quien forjó

\footnotetext{
${ }_{16}$ ĺdem.

17 Ídem.

${ }^{18}$ Barili, Roberto. La Obra de Don Lorenzo Scaglia. Revista del Museo Municipal de Ciencias Naturales y Tradicional de Mar del Plata [en adelante RMMCNyT MDP], 1952, 1 (1):5, MGP.

${ }^{19} B M$, Creación del Museo Regional, Histórico y Tradicional de Mar del Plata. Exp. 76-I-1938, 2do Trimestre 1938: 83. /Diario La Capital, Creóse el Museo Regional, Histórico y Tradicionalista de Mar del Plata. 28/04/1938. MDP.
}

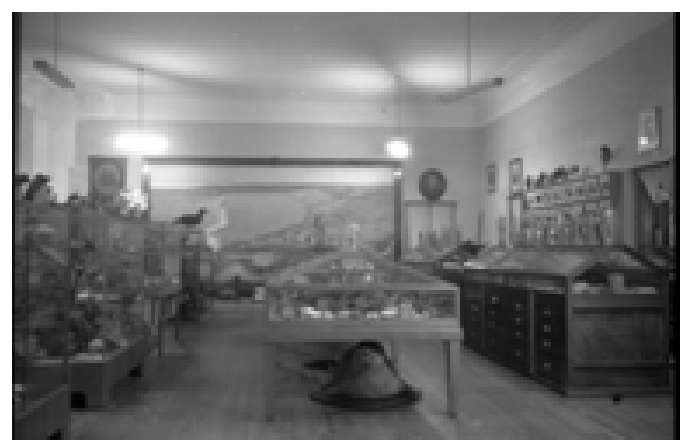

Figura 3. Primer sede del museo en un salón del Palacio Municipal. Gentileza Museo de Ciencias Naturales Lorenzo Scaglia.

Figure 3: First location of the museam placed in a room of the Municipal Palace. Courtesy of the Natural Science Museam "Lorenzo Scaglia"

con su esfuerzo personal la colección que hiciera posible el primer museo de Mar del Plata. Entre los considerandos incluidos en el decreto firmado por el intendente municipal se planteaba la necesidad de una reconstrucción del pretérito de la ciudad que señalara una continuidad cronológica que abarcara desde "la llegada del primer poblador de suerte que, permitiría seguir paso a paso, las etapas graduales ascendentes que marcan su progreso desde aquella época hasta nuestros días" 20 . En un contexto de gestión provincial basado en la constitución de museos de historia, la autorización para la creación del museo fue impulsada por Ricardo Levenne quien la presentó ante la Comisión Nacional de Museos (Blasco 2007). Levenne, que formaba parte de los invitados especiales que habían sido convocados para la inauguración de 1936, había jugado un rol preponderante en la organización/profesionalización del saber histórico y su articulación con el sistema educativo a través de su creciente influencia política como historiador principal de la Junta de Historia y Numismática Americana, que a partir de 1938 se convertiría en la Academia Nacional de la Historia. El museo que había nacido a partir del interés por la historia natural encuentra en otro historiador, Julio César Gascón, a su primer director. Durante su pasaje por el museo comenzó a formarse el archivo histórico de la ciudad de Mar del Plata que se nutría de un corpus documental apógrafo compuesto por informes, resoluciones gubernativas, correspondencia particular, planos de mensuras catastrales además de los aportes realizados por vecinos de la ciudad que fueron aumentando la disponibilidad de fuentes a consultar ${ }^{21}$.

Gascón permaneció brevemente al frente de la institución hasta que, luego de su renuncia, fue reemplazado por Galileo J. Scaglia22. Éste último, hijo de Lorenzo, fue

\footnotetext{
${ }^{20}$ BM, 2do trimestre 1938: 83, MDP/ BM, Director del "Museo Municipal de Ciencias Naturales y Tradicional de Mar del Plata, Mayo 1948, 115:10-11 y 19.

${ }^{21}$ BM, El Museo Regional, Histórico y Tradicional de Mar del Plata, Primer Trimestre, 1939: 67.

${ }^{22}$ BM, Director del Museo Municipal, Mayo y Junio de 1940:7.
} 


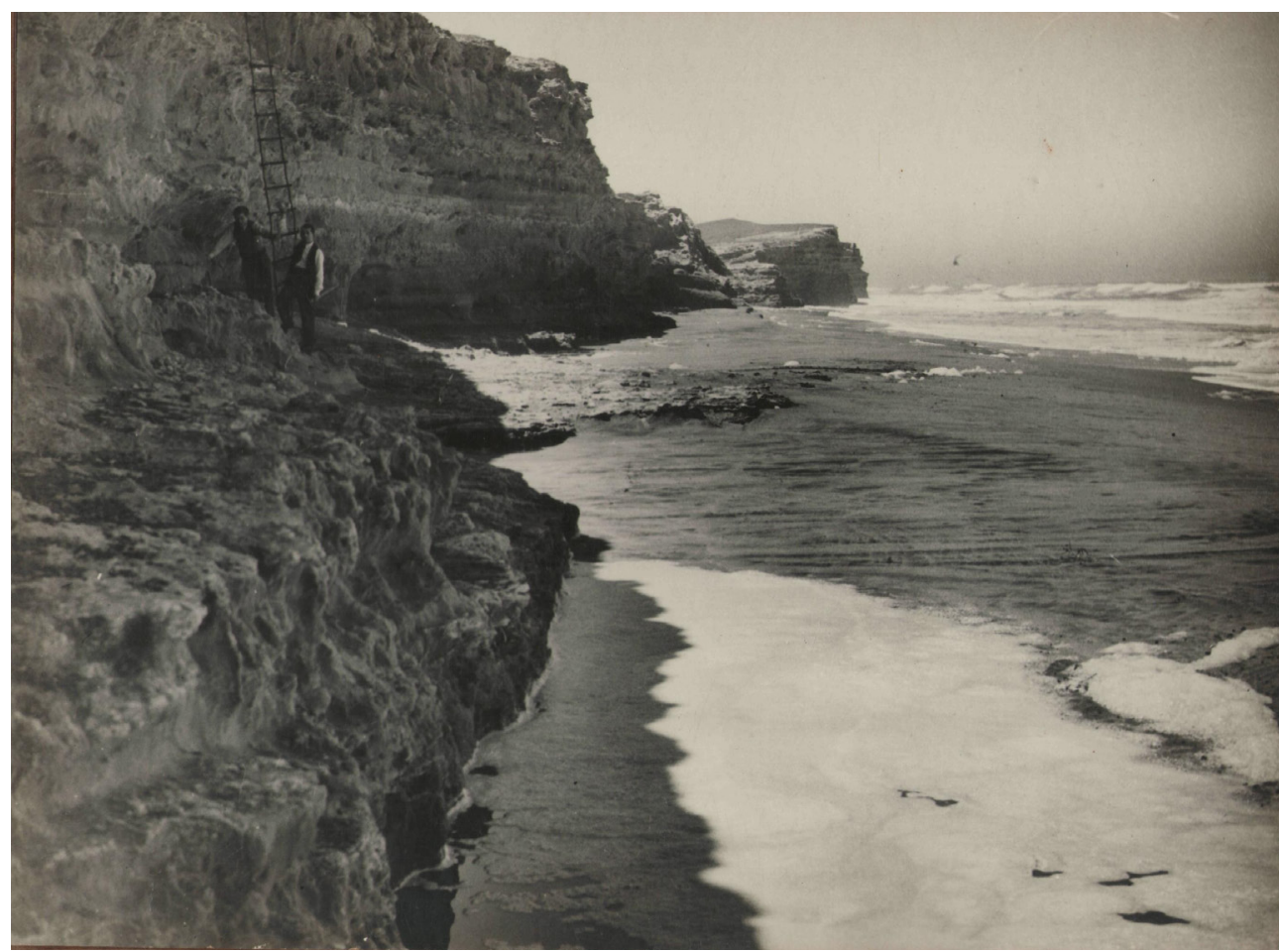

Figura 4. Lorenzo y Galileo Scaglia realizando trabajos en las barrancas costeras. Gentileza de la familia Scaglia.

Figure 4: Lorenzo and Galilleo Scaglia working at a coastal storage. Courtesy of Scaglia's family.

designado como director interino por el comisionado municipal Arturo J. Livingston en $1940^{23}$. Aunque la política provincial condujera a la gestación de museos de historia (Pupio 2005, Blasco 2007), durante la década del cuarenta se asistió al surgimiento tanto en Buenos Aires como en otras provincias de centros de aficionados y coleccionistas que, al igual que el primer museo municipal de Mar del Plata, colaboraron activamente con el Museo de La Plata (Reig 1962).

G. Scaglia dio continuidad a la obra paterna, Osvaldo Reig, paleontólogo y contemporáneo de aquel, así describe su aporte:

"Desde esta institución, Scaglia realiza una intensa campaña en la explotación de nuestros principales yacimientos de mamíferos fósiles, tanto en la provincia de Buenos Aires como en la Patagonia (...) Los descubrimientos de Scaglia han deparado novedades de gran interés. Su talento excepcional como coleccionista y preparador, ha hecho que su colaboración sea reclamada por los principales centros paleontológicos del país, y en los últimos años ha sido el principal animador de expediciones de gran aliento. Se debe a Scaglia y a la institución marplatense lo fundamental de los descubrimientos realizados en los últimos quince años (1962: 97-98)".

\footnotetext{
${ }_{23} B M$, Asignación Pensión a Don Lorenzo Scaglia, Mayo 1948, 115: 18-19.
}

Además de la inmensa riqueza paleontológica con la cual también se acrecentaba la colección original de L. Scaglia, el ingreso de piezas arqueológicas se fue incrementando y documentando progresivamente como parte del acervo del museo ${ }^{24}$. El regreso de los Scaglia implicó un retorno al rumbo inicial del museo. Sin embargo, la breve permanencia de Julio Gascón al frente dejó entrever la necesidad latente de la constitución de nuevos espacios vinculados con lo histórico, el tradicionalismo y las artes. Dentro de la planificación emprendida durante las décadas del cuarenta y cincuenta a nivel nacional y provincial se proyecta la construcción de un edificio propio donde se alojaría un Instituto de Cultura que incluiría la Biblioteca Pública Municipal, un Museo de Arte y un Museo Tradicional25.

En el año 1967 y durante la dirección de Galileo Scaglia, el museo se traslada a su sede actual en la Plaza España ${ }^{26}$. Para entonces se había establecido un fluido intercambio científico con distintos museos nacionales entre los que pueden mencionarse los de Buenos Aires, Tucumán, La Plata así como, otros regionales. La Colección Scaglia

\footnotetext{
${ }^{24}$ Se observaron los informes de ingreso de material al Museo publicados en el Boletín Municipal entre los años 1948 y 1954 . Entre las secciones, en las cuales se registra la incorporación de piezas, se encuentran las de Paleontología, Arqueología, Mineralogía, Numismática, Ornitología, Malacología. La mayoría de ellas corresponden al universo de las Ciencias Naturales.

${ }^{25}$ BM, Construcción del Edificio de la Cultura, Marzo y Abril de 1945: 36- 41.

${ }^{26}$ La Capital, Se inaugura el Museo de Ciencias Naturales, 4/12/1967.
} 
fue donada a fin de integrar el patrimonio público local.

\section{Los Scaglia y el amateurismo}

Lorenzo Scaglia, de origen italiano, se había establecido en Mar del Plata en el año 1920 habiendo cursado sus estudios primarios en Alfianello, en la región de Lombardía, en la provincia de Brescia ${ }^{27}$. Llega en 1897 a Argentina a sus veinte años de edad junto a dos hermanos. El mayor de ellos, Antonio, se instala en la ciudad de Rosario -Santa Fe- mientras que el menor, Juan, se queda junto a Lorenzo en Adrogué -provincia de Buenos Aires. Lorenzo estudia violín, se dedica a la carpintería y más adelante prueba suerte con la siembra de trigo en cercanías de Laguna La Brava en inmediaciones de las sierras de Balcarce, otro partido colindante. Contrae matrimonio con María Regina Magnani con quien tiene cinco hijos. Ya en Mar del Plata arrienda unas cuatro manzanas a Peralta Ramos en las que realiza tareas de carpintería, venta de hielo en el verano y trabajos en herrería y mecánica. Aquel sería el asiento de la llamada "Chacra de don Lorenzo" en donde acondicionaba y exponía los restos de mamíferos fósiles que recolectaba en las barrancas costeras. Su admiración por los ejemplares fosilizados la había experimentado por primera vez en su tierra natal cuando exploraba las riberas de un río cercano junto a su maestro de tercer grado. Los paisajes serrano y costero volvieron a despertar en él esa curiosidad innata que se intensificó en 1922 al descubrir un molar de mastodonte extinto. Es entonces donde retoma su práctica aficionada incorporando en ella a sus dos hijos: Galileo y Movimiento Carlos $^{28}$. Y aunque un desafortunado episodio en el campo se llevó la vida de uno de ellos, aquella circunstancia no impidió que L. Scaglia continuara trabajando en la exploración de yacimientos fósiles de la región. Incluso llegó a contar con el reconocimiento oficial, por parte de sus contemporáneos.

Así, entra en contacto con el entonces director del Museo de Ciencias Naturales de La Plata, doctor Luis María Torres, quien además de interesarse por los fósiles conseguidos por Lorenzo Scaglia, ofrece apoyo para su hijo Galileo a fin que prosiguiera estudios en paleontología. Lamentablemente esa posibilidad no se concreta pero marca el inicio de una fructífera labor que llevará adelante Galileo en el Museo.

Lorenzo Scaglia falleció el 14 de Julio de 1954 cuando la institución, cuya creación había alentado, había adquirido una segunda denominación: Museo Municipal de Ciencias Naturales y Tradicional de Mar del Plata, en la actualidad reconocido como Museo de Ciencias Naturales Lorenzo Scaglia.

\footnotetext{
27 Barili, Roberto. 1989. Los Italianos en Mar del Plata. Instituto Gráfico Italiano. Volúmen II. Parte de los datos biográficos del presente apartado fueron extraídos del texto citado.

${ }^{28}$ Kraglievich, J. "Lorenzo Scaglia". Necrología. RMMCNyT MDP, 1954,

1 (2):170-171, MGP.
}

La Revista del Museo, que había comenzado a editarse exitosamente en el año 1952, dedicó algunas páginas a la figura de Don Lorenzo Scaglia. En ellas se reprodujo el discurso que Jorge L. Kraglievich, hijo de Lucas Kraglievich y entonces sub-director del Museo Municipal de Ciencias Naturales y Tradicional de Mar del Plata hiciera en sus funerales. El mencionado destacó tres aspectos característicos de la personalidad de L. Scaglia así como de su labor en el sudeste de la costa atlántica bonaerense: 1) el esfuerzo personal vinculado con la austeridad y la tendencia a solventar con recursos propios la cultura; 2) la caracterización de la ciencia como popular; y 3) el cariz autodidacta de estos naturalistas. Los dos primeros elementos que destaca se sintetizan en su dedicación por poner la "ciencia al alcance del pueblo" según lo refiere Kraglievich. Continúa indicando que dicho propósito significó para L. Scaglia "continuos viajes por la República costeados personalmente con el fruto de su honrada labor cotidiana"29. La frase descubre de qué forma el altruismo y el voluntarismo personal se presentan en favor de una ciencia, pensada para el pueblo y llevada adelante por gestores modestos.

La imagen atribuida a L. Scaglia recuerda la figura del sabio que sobre él se proyecta ya que, al igual que a $\mathrm{F}$. Ameghino con su hermano Carlos, incluyó a su familia, en su caso a sus hijos, en las actividades de campo. Asimismo, las necesidades materiales eran solventadas a través de su negocio particular.

El tercer punto que destaca J. Kraglievich corresponde al carácter autodidacta de la formación de L. Scaglia:

"Su ejemplo hermoso, lleno de contenido y de enseñanzas, es el de un hombre del pueblo, esencialmente humilde, que, sin haber podido adquirir en su juventud una formación científica sistemática, supo poner su tesón y sus ideales en juego para concretar una obra de vastas proyecciones en el campo intelectual, como lo es la creación y propulsión de un centro de investigaciones y de la difusión cultural con perfiles propios ${ }^{30 "}$.

Nuevamente aquí, el esfuerzo personal reemplaza las carencias materiales, el altruismo la demora en el reconocimiento y la educación autodidacta la formación más específica. El olvido, la austeridad, la necesidad de generar recursos propios y el profundo desinterés personal son todas cualidades que se extraen tanto de los homenajes a F. Ameghino como en los obituarios dedicados a la memoria de Lorenzo Scaglia.

Existen otros hechos que sostienen esta cercanía en la proyección de las figuras de Florentino Ameghino y Lorenzo Scaglia, como por ejemplo, que la desaparición física del segundo coincidiera con el octogésimo aniversario del natalicio del primero, ocurrido en 1874. Con motivo

\footnotetext{
${ }^{29}$ Ídem.

30 Ibídem.
} 
del nuevo aniversario, la Municipalidad designó una comisión especial para organizar nuevos festejos. Los mismos, que consistieron en el descubrimiento de una placa recordatoria del sabio y su obra, contaron con una concentración de escolares frente a la efigie de F. Ameghino con presencia de autoridades municipales, jefes del ejército y la marina. Los días previos, J. Kraglievich junto a Nolberto Pezzati, recordaron a F. Ameghino en la radio local, L.U. 6 Radio Atlántica, y el día 18 de septiembre, se realizó otro homenaje público en el Club Social General Pueyrredón del cual participó el subdirector del museo ya mencionado y representantes de la Comisión Social y de la Alianza Francesa en Mar del Plata $^{31}$. El recuerdo de F. Ameghino permanecía latente.

El homenaje al sabio de 1936 se transformó así en el acto fundacional que puso en escena pública la relación existente entre la materialidad del pasado a través de la evidencia geológica, paleontológica y arqueológica con sentimientos tan disciplinantes y emotivos como los ideales cívicos de la nacionalidad. En este sentido, si bien coincidimos con los investigadores que indican la ausencia de un plan rector del estado asociado a la nacionalidad, podría decirse que el afloramiento de estas personalidades resulta en oportuna coincidencia con el momento político social del país donde, la nacionalidad y la identidad local, ambas en continua formación, se complementaron. Asimismo, cabe destacar que a partir de la década de 1950 también se da un cambio con relación a la administración política de los museos contenidos en ámbitos municipales de la provincia de Buenos Aires. Durante las gestiones de los gobernadores de la provincia de Buenos Aires, Domingo Mercante (1946-1951) y Carlos Vicente Aloe (1951-1955) se promovió una política centralizada desde la provincia donde se consideraba a los museos como instituciones educativas con fines pedagógicos, cuyas acciones debían estar orientadas hacia una misma política cultural del estado tendiente a: "que todas las instituciones museísticas del territorio de la provincia, dependientes del poder provincial, municipal o de la órbita privada se rigieran bajo pautas comunes" (Pupio 2005: 213). Aunque dicha política sólo pudo llevarse adelante durante los años de las gestiones mencionadas, debido al golpe de estado del año 1955, el cambio en la política cultural permite abrir un paréntesis prácticamente simultáneo con el deceso de L. Scaglia y el octogésimo aniversario del nacimiento de F. Ameghino, acontecimientos que delinean el corolario de una etapa y un punto de enclave para el desarrollo de las instituciones museológicas durante el siglo XX.

\section{A modo de conclusión}

La institución que fue concebida en la década de 1920 y que pudo constituirse como tal en 1938 a instancias del

\footnotetext{
${ }^{31}$ RMMCNyT MDP, "Florentino Ameghino" 1854- 18 de Septiembre1954. Actos conmemorativos del centenario de su nacimiento", 1954, 1 (2): 173-174, MGP.
}

amateur Lorenzo Scaglia estuvo ligada a la figura medular de quien se había constituido en el hombre de ciencia argentino: Florentino Ameghino. La obra de Florentino no se había desarrollado en soledad sino con la gran colaboración de su hermano Carlos quien efectuaba tareas de exploración y búsqueda de campo. El ideal cívico atribuido a la figura de Florentino Ameghino, al condensar virtudes morales asimilables voluntariamente por la mayoría de la comunidad, tornaba accesible e imitable su ejemplaridad mientras dotaba a dicha imagen de sentidos antiguos y nuevos.

En esa vía, los homenajes al sabio se enfocaron en la formación de una pertenencia afín a la diversidad de intereses que se buscaban conciliar y cristalizar en la escena pública local. Al mismo tiempo, estuvieron teñidos de las opiniones que surgían de los debates políticos concernientes a la administración municipal. De esta forma, la imagen de Ameghino pasó de representar los postulados del socialismo a convertirse en bandera del nacionalismo en una síntesis de los principales atributos morales ejemplares asignados a su figura.

Lorenzo Scaglia de origen italiano, que se había dedicado a una tarea artesanal y de conocimiento práctico e informal a través de la autodidaxia, y que financió con recursos propios, representó a nivel local una figura de prestigio. Bajo dicho amparo se descubrió un espacio científico particularizado por la tarea de campo desarrollada por Lorenzo Scaglia y perfeccionada luego por Galileo Scaglia. Mientras Lorenzo introdujo a su hijo en la exploración, extracción y en la experimentación para acondicionar los fósiles de las barrancas costeras, Galileo profundizó en la preparación de esas piezas y, de otras nuevas, que acrecentaron la colección original.

Asimismo, que el museo haya nacido formalmente en un contexto de gestión provincial definido por la presencia de los historiadores Levenne - a nivel provincial- y Gascón - a nivel local-, no anula una impronta naturalista que es visible en una trayectoria más amplia. Naturalismo y coleccionismo/amateurismo encuentran bajo la forma del Museo Regional y Municipal, un espacio de mayor autonomía en un contexto de profesionalización disciplinar en el que la práctica aficionada de la arqueología y la paleontología se hallaban en franco retroceso. De esta forma queda expuesto como ciencia, cultura y política se amalgaman en más de un sentido posible.

Mar del Plata, 25 de Abril de 2012.

\section{Agradecimientos}

Al Museo de Ciencias Naturales "Lorenzo Scaglia" y a la Hemeroteca Pública Municipal del Partido de General Pueyrredón. Parte de este trabajo fue presentado en el $\checkmark$ Congreso de Arqueología de la Región Pampeana Argentina en la Universidad Nacional de La Plata en 
el año 2011. Su contenido forma parte del proceso de investigación doctoral en curso (UNCPBA - Tandil) en el marco del programa de becas de postgrado (CONICET). Asimismo es el producto de investigaciones realizadas como integrante de proyectos de investigación financiados por la ANPCyT (PICT 2008, N 1390) y la UNMDP.

\section{Bibliografía}

Anderson, B. 1993. Comunidades Imaginadas. Reflexiones sobre el origen y la difusión del nacionalismo. FCE, México.

Bartolucci, M. 2002. Mar del Plata. Imágenes urbanas, vida cotidiana y sociedad. 1874-1990. Mar del Plata. Área Editorial. Departamento de Historia. UNMDP.

Barrancos, D. 1996. La escena iluminada. Ciencia para los trabajadores 1890-1930. Plus Ultra. Buenos Aires.

Bertoni, L. 2001. Patriotas, cosmopolitas y nacionalistas. La construcción de la nacionalidad argentina a fines del siglo XIX. FCE. Buenos Aires.

Blasco, M. E. 2007. Los museos históricos en la Argentina entre 1889 y 1943. Historiapolítica.com. Programa Buenos Aires de Historia Política del siglo XX. http:// historiapolitica.com/datos/biblioteca/blasco1.pdf (última consulta: 27/03/2012).

Bonomo, M. 2002. El Hombre Fósil de Miramar. Intersecciones en antropología, 3: 69-87.

Carretero, M. 2007. Documentos de Identidad. La construcción de la memoria histórica en un mundo global. Paidós, Buenos Aires.

Conforti, M. 2010. Educación no formal y patrimonio arqueológico. Su articulación y conceptualización. Intersecciones en Antropología, 11:103-114.

Daino, L. 1979. Exégesis histórica de los hallazgos arqueológicos de la costa atlántica bonaerense. Prehistoria bonaerense. 1979. Año del Centenario de la Conquista del desierto. Municipalidad de Olavarría: 93-195.

Da Orden, L., E. Pastoriza. 1991. La formación de una ciudad moderna. Grupos sociales y ámbitos culturales, AAVV, Mar del Plata. Una Historia urbana, capítulo V, 165-207, Fundación Banco de Boston, Buenos Aires.

Endere, M. L. 2011. Cacique Inakayal. La primera restitución de restos humanos ordenada por Ley. Corpus. Archivos virtuales de la alteridad americana. 1 (1). http:// ppct.caicyt.gov.ar/index.php/corpus (última consulta 1/06/2013).
Endere, M. L. 2008. Algunas reflexiones acerca del patrimonio. Endere, M.L. y J.L. Prado, Patrimonio, ciencia y comunidad. Un abordaje preliminar en los partidos de Azul, capítulo 1, 17-46, Incuapa, Olavarría y Tandil.

Endere, M. L., I. Podgorny. 1997. Los Gliptodontes son argentinos. Ciencia Hoy. v. 7, n. 42, http//:www. cienciahoy.org.ar/hoy42/glipt2.htm (última consulta 27/03/2012).

Farro. M. 2008. Redes y medios de transporte en el desarrollo de expediciones científicas en Argentina. 1850-1910. História, Ciências, Saúde Manguinhos, 15 (3): 679- 696.

Farro, M., I. Podgorny. 1998. Frente a la tumba del sabio. Florentino Ameghino y la santidad del científico en el Plata. Ciencia Hoy. 8 (47): 28-37.

García Costa, V. 1997. Alfredo Palacios. Entre el clavel y la espada. Una biografía. Planeta, Buenos Aires.

Guber, R., M. Bonnin y A. Llaguens. 2007. Tejedoras, topos y partisanos. Prácticas y Nociones acerca del trabajo de campo en la Arqueología y la Antropología Social en Argentina. Relaciones de la Sociedad Argentina de Antropología. 32: 381-406.

Hobsbawm, E. Historia del siglo XX, 1914-1991. 1996. Crítica Grijalbo Mondadori, Barcelona.

Jofre, Jorge, María Liliana Da Orden y Elisa Pastoriza. 1991. La vida política. AAVV, Mar del Plata. Una Historia urbana, IV, 93-164, Fundación Banco de Boston, Buenos Aires.

Masotta, C. 2007. Indios en las primeras postales fotográficas argentinas del s. XIX. La Marca editora, Buenos Aires.

Pastoriza, E., J. C. Torre. 1999. Mar del Plata, un sueño de los argentinos. Madero, M., F. Devoto, Historia de la vida privada en la Argentina, 49-75, Taurus, Buenos Aires.

Pastoriza, E. 2008. Estado, gremios y hoteles. Mar del Plata y el peronismo. Estudios Sociales, 34 (primer semestre):121-147.

Pegoraro, A. 2003. Estrategias de formación de colecciones del Museo Etnográfico durante el período 1904-1917. Historias de la Ciencia Argentina I. César Lorenzano (editor). Eduntref, Tres de Febrero: 17-28.

Podgorny, I, G. Politis. 1990-1992. ¿Qué sucedió en la Historia? Los esqueletos Araucanos del Museo de la Plata y la conquista del Desierto. Arqueología contemporánea, 1: 73-79.

Podgorny, I. 1997. De la santidad laica del científico 
Florentino Ameghino y el espectáculo de la ciencia en la Argentina moderna. Entrepasados, 13: 37-61.

Podgorny, I. 2000. El argentino despertar de las faunas y de las gentes prehistóricas. Coleccionistas, museos, estudiosos y universidad en la Argentina, 1875-1913. Libros del Rojas. Buenos Aires.

Podgorny, I. 2004. "Tocar para creer". La arqueología en Argentina, 1910-1940. Anales del museo de América, 12: 147-182.

Podgorny, I. 2009. El sendero del tiempo y de las causas accidentales. Los espacios de la prehistoria en la Argentina, 1850-1910. Prohistoria. Rosario.

Pupio, A. 2011. Coleccionistas, aficionados y arqueólogos en la conformación de las colecciones arqueológicas del Museo de La Plata, Argentina (1930-1950). Coleccionismos, Prácticas de campo e representacões. Alda Heizer y Margaret Lopes (editores). Campina Grande.
EDUEPB: 269-280.

Pupio, A. 2005. Coleccionistas de objetos históricos, arqueológicos y de ciencias naturales en museos municipales de la provincia de Buenos Aires en la década de 1950. História, Ciências, Saúde - Manguinhos, 12: 205-29.

Ramundo, P. 2008. Medio siglo de formación académica en Arqueología: Avances y Cuentas Pendientes. La Zaranda de Ideas. Revista de Jóvenes Investigadores en Arqueología. 4: 141-146. Buenos Aires.

Reig, O. 1962. La paleontología de vertebrados en la Argentina. Retrospección y prospectiva. Holmbergia. Revista del centro de estudiantes de ciencias naturales, 17 (VI): 68-117.

Romero, L. 2004. La Argentina en la escuela. La idea de nación en los textos escolares. Siglo XXI, Buenos Aires. 